\title{
UMA ABORDAGEM DA ERGOLOGIA AO TRABALHO DOS CATADORES DE MATERIAIS RECICLÁVEIS
}

\author{
AN ERGOLOGY APPROACH TO THE WORK OF WASTE PICKERS
}

\section{UN ENFOQUE DE ERGOLOGÍA PARA EL TRABAJO DE LOS RECOLECTORES DE MATERIALES RECICLABLES}

\section{Luiz Phillipe Mota Pessanha ${ }^{\mathrm{i}}$}

\author{
Alexandre de Carvalho Castro
}

\begin{abstract}
Resumo: O problema dos resíduos sólidos, ou lixo urbano, é de natureza complexa quanto ao seu gerenciamento e crescente quanto as grandes quantias de resíduos geradas nos centros urbanos. Dentro desse cenário, a figura do catador aparece como elo importante para que as atividades de gerenciamento dos Resíduos Sólidos Urbanos (RSU) sejam efetivamente praticadas. Esses catadores, recém reconhecidos como profissionais, organizam-se, em geral, em cooperativas de reciclagem, onde desempenham atividades, que demandam desgaste físico, em condições de trabalho insuficientes ou inadequadas. Nesse sentido, discute-se aqui a importância do trabalho dos catadores de materiais recicláveis e a Ergologia como abordagem teórico-metodológica para análise do trabalho desses profissionais, considerando melhores condições de vida e trabalho e com pretensões a aumentar a visibilidade social sobre esses trabalhadores.
\end{abstract}

\begin{abstract}
The problem of solid waste, or urban waste, is complex in its management and growing in relation to the large amounts of waste generated in urban centers. Within this scenario, the figure of the waste pickers appears as an important link for the activities of management of Urban Solid Waste to be effectively practiced. These garbage collectors, recently recognized as professionals, organize themselves, in general, in recycling cooperatives, where they perform activities that high physical demand, in insufficient or inadequate working conditions. In this sense, we discuss here the importance of the work of recyclable material collectors and Ergology as a theoretical-methodological approach to analyze the work of these professionals, considering better living and working conditions and with intentions to increase the social visibility of these workers.
\end{abstract}

Resumen: El problema de los residuos sólidos es complejo en su gestión y crece en relación con las grandes cantidades de residuos generados en los centros urbanos. Dentro de este escenario, la figura del recolector aparece como un vínculo importante para que las actividades de gestión de Residuos Sólidos Urbanos (RSU) se practiquen de manera efectiva. Estos carroñeros, recientemente reconocidos como profesionales, se organizan, en general, en cooperativas de reciclaje, donde realizan actividades que exigen desgaste físico, en condiciones de trabajo insuficientes o inadecuadas. En este sentido, discutimos aquí la importancia del trabajo de los recolectores de materiales reciclables y la Ergología como un enfoque teórico-metodológico para analizar el trabajo de estos profesionales, considerando mejores condiciones de vida y trabajo y con la intención de aumentar la visibilidad social de estos trabajadores.

Palavras-chave: Análise do Trabalho; Ergonomia da Atividade; Resíduos Sólidos.

Keywords: Work Analysis; Activity Ergonomics; Solid waste.

Palabras claves: Análisis laboral; Actividad ergonómica; Residuos sólidos. 
O foco deste estudo, em desenvolvimento no doutorado em Engenharia de Produção, gira em torno da análise do trabalho de catadores em cooperativas de reciclagem. Nesse sentido, se insere em um cenário sócio-histórico bastante complexo.

O crescimento populacional, os avanços tecnológicos e o desejo, por vezes induzido pela mídia, dos consumidores em adquirir produtos lançados recentemente aumentam os impactos negativos do processo produtivo e pós-consumo, levando, por exemplo, ao aumento da geração de Resíduos Sólidos Urbanos (RSU) (KIM et al, 2018).

Segundo ABRELPE (2017), no ano de 2017 o Brasil gerou 78,4 milhões de toneladas de RSU e deste montante $91,2 \%$ foi coletado. Considerando o material coletado, 59,1\% foi destinado para aterros sanitários e 40,9\% restante foi despejado em locais inadequados, como os lixões. Estes dados indicam que o Brasil não atingiu uma das metas estabelecidas na Lei n ${ }^{\circ}$ 12.305/10, que institui a Política Nacional de Resíduos Sólidos (PNRS), sendo essa a erradicação dos lixões até o ano de 2014.

A PNRS também pressupõe os sistemas de Logística Reversa, emergentes em países em desenvolvimento, como caso do Brasil, e que enfrentam problemas como lacunas na legislação, falta de incentivos econômicos, baixa conscientização dos consumidores e catadores de materiais recicláveis que coletam e destinam quantidades crescentes de RSU com pouco preparo para lidar com os riscos relativos à saúde, à segurança e à proteção do meio ambiente (DEMAJOROVIC, AUGUSTO e SOUZA, 2016).

A profissão dos catadores no Brasil é reconhecida pela Classificação Brasileira de Ocupações - CBO em 2002 e descreve as tarefas desse profissional como:

\footnotetext{
Os trabalhadores da coleta e seleção de material reciclável são responsáveis por coletar material reciclável e reaproveitável, vender material coletado, selecionar material coletado, preparar o material para expedição, realizar manutenção do ambiente e equipamentos de trabalho, divulgar o trabalho de reciclagem, administrar o trabalho e trabalhar com segurança (BRASIL, 2019).
}

Os catadores atuam comumente nos seguintes espaços de trabalho: nas ruas, nos lixões, nos aterros sanitários e nas unidades de triagem ou cooperativas, estando em sua maioria imersos no mercado informal de trabalho (GALON e MARZIALE, 2016). O trabalhador é exposto a variações climáticas, a riscos de acidente na manipulação do material, a acidentes de trânsito e, muitas vezes, à violência urbana. Nas cooperativas surgem especializações do trabalho que tendem a aumentar o número de postos, formando um 
processo que compõe parte importante da cadeia produtiva de reciclagem. Alguns postos de trabalho são os de separador, triador e enfardador de sucatas, para citar algumas (MNCR, 2014).

Considerando as condições precárias de vida, trabalho e saúde dos catadores informais e a necessidade de promoção de políticas públicas favoráveis ao gerenciamento adequado dos RSU e à inclusão digna desses trabalhadores no mercado laboral, tem-se como objetivo, nessa pesquisa de doutorado que está sendo desenvolvida, analisar as condições de trabalho e saúde de catadores de materiais recicláveis em cooperativas, considerando a abordagem da Ergonomia da Atividade.

A Ergologia, abordagem convergente com Ergonomia da Atividade (SCHWARTZ, 2013), é um modo diferente de enxergar a atividade de trabalho que deve ser examinado sob a ótica do trabalhador, e não sob a ótica organizacional - como preza a Ergonomia tradicional. Essa abordagem possui uma característica bastante particular e única, que estuda os saberes que emergem dos próprios trabalhadores, através de notoriedades intrínsecas aos sujeitos e suas relações com as atividades de trabalho desempenhadas. Ou seja, para entendermos o trabalho, seu sentido e suas repercussões, é preciso colocar no centro da discussão o saber dos trabalhadores, sua experiência, o que sabem e como sabem (VINAGRE e CASTRO, 2017; VIEIRA, BARROS e LIMA, 2007).

Nessa abordagem, a característica essencial da análise do trabalho é examinar o que acontece na complexidade da realidade. Assim, considera-se uma distinção entre o trabalho real e prescrito, a tarefa e a atividade, as semânticas da situação e o desenvolvimento do curso de ação do trabalhador (ABRAHÃO e PINHO, 2002).

É importante ressaltar que o trabalho prescrito (tarefa) e real (atividade) estabelecem uma relação de complementar, não configurando faces opostas do trabalho. As prescrições podem contribuir diretamente para o desenvolvimento das atividades. Em outros casos, podem ser ineficazes levando a discussão sobre qual prescrição é realmente pertinente (BRITO, 2006).

$\mathrm{Na}$ Ergonomia da atividade a análise do trabalho considera o trabalhador como sujeito ativo do processo, pois dependendo da situação com a qual ele é confrontado, ele transforma permanentemente sua atividade, como forma de responder as demandas que se apresentam (ABRAHÃO e PINHO, 2002).

A Ergonomia da Atividade utiliza-se de conceitos importantes para sua compreensão e análise do trabalho, tais como usos de si, normas antecedentes, renormatizações, 
Dispositivo Dinâmico de 3 Polos e Instrução ao Sósia (SCHWARTZ, 2013; HOLZ, 2013; CLOT, 1999).

Esse horizonte teórico-metodológico foi abordado porque espera-se, nesta pesquisa, compreender como os conceitos citados acima podem ser empregados para analisar o trabalho de catadores em cooperativas de reciclagem, considerando a abordagem da ergologia e da ergonomia da atividade, ou seja, compreendendo sobre o ponto de vista da atividade os riscos a que esses trabalhadores estão expostos, as especificidades da profissão e as contribuições que podem ser geradas para minimização dos riscos à saúde e consequentes melhorias no dimensionamento do ambiente de trabalho.

Para tanto, serão realizadas visitas de imersão em cooperativas de reciclagem onde se buscará observar a organização do trabalho, as atividades realizadas, além de utilizar-se de entrevistas com os trabalhadores para através do diálogo compreender o trabalho real desse profissional. A partir desses dados, serão feitas análises com intenção de atingir os objetivos propostos por essa pesquisa.

As justificativas para esse estudo são muitas. No entanto, destaca-se a expectativa de contribuir para melhores condições de trabalho para os catadores, recém reconhecidos como profissionais, e que em uma perspectiva econômica enfrentam desvalorização do seu trabalho com baixa remuneração. Além disso, os catadores ainda não contam com nenhuma proteção trabalhista efetiva, caso necessitem de afastamento por problemas de saúde e/ou acidentes de trabalho, situação que gera preocupação e sofrimento para esses trabalhadores (MEDEIROS e MACEDO, 2007).

Por fim, no longo prazo, essa pesquisa irá contribuir para as práticas de sustentabilidade, uma vez que o catador de material reciclável é um elo importante dentro da cadeia de suprimentos reversa, facilitando, assim, o cumprimento da PNRS instituída no país a 9 anos e que ainda enfrenta obstáculos na sua implementação e controle.

\section{REFERÊNCIAS}

ABRAHÃO, J. I.; PINHO, D. L. M.. As transformações do trabalho e desafios teóricosmetodológicos da Ergonomia. Estudos de Psicologia, Brasília, n. 7, p.45-52, 2002.

ABRELPE - ASSOCIAÇÃO BRASILEIRA DE EMPRESAS DE LIMPEZA PÚBLICA E RESÍDUOS ESPECIAIS. Panorama dos Resíduos Sólidos no Brasil 2017. São Paulo -SP, 2017.

BRASIL. MINISTÉRIO DO TRABALHO. Trabalhadores da coleta e seleção de material reciclável. Disponível em: $<$ http://www.mtecbo.gov.br/cbosite/pages/pesquisas/BuscaPorTituloResultado.jsf $>$. Acesso em: 27 fev. 2019.

BRITO, J. Trabalho Real. In: Escola Politécnica de Saúde Joaquim Venâncio - Observatório dos Técnicos em Saúde. Dicionário da Educação Profissional em Saúde. Rio de Janeiro: Fiocruz, 2006. 
CLOT, Y. La fonction psychologique du travil. Paris: PUF, 1999.

DEMAJOROVIC, J.; AUGUSTO, E. E. F.; SOUZA, M. T. S. Logística Reversa de REEE em Países em Desenvolvimento: Desafios e Perspectivas para o Modelo Brasileiro. Ambiente \& Sociedade, São Paulo, v. 19, n. 2, p.119-138, 2016.

GALON, T.; MARZIALE, M. H. P. Catadores de materiais recicláveis: um encontro nacional. Rio de Janeiro: Ipea, p. 562, cap. 7, 2016.

HOLZ, E.B. Dispositivo dinâmico de três polos e metodologia geral em ciências sociais: discutindo uma analogia. Trabalho \& Educação, Belo Horizonte, v.22, n.2, p.155-167, 2013.

KIM, V. J. H.; CONTE, G. G.; OMETTO, A. R.; SCHALCH, V. Similaridade entre os conceitos de Economia Circular e Política Nacional de Resíduos Sólidos (PNRS). In: FÓRUM INTERNACIONAL DE RESÍDUOS SÓLIDOS, 9. Anais... Porto Alegre, 2018. p. 12 - 20.

MEDEIROS, L. F. R.; MACEDO, K. B. Profissão: catador de material reciclável, entre o viver e o sobreviver. Revista Brasileira de Gestão e Desenvolvimento Regional, v. 3, n. 2, p. 72-94, 2007. Disponível em: < http://www.rbgdr.net/022007/artigo4.pdf>.

MNCR - MOVIMENTO NACIONAL DOS CATADORES DE MATERIAIS RECICLÁVEIS. Classificação Brasileira de Ocupações - CBO. 2014. Disponível em: $<$ http://mncr.org.br/biblioteca/legislacao/classificacao-brasileira-de-ocupacoes-cbo $>$. Acesso em: 01 mar. 2019.

VINAGRE, R. F.; CASTRO, A. de C. Da contribuição da ergonomia aos aportes da ergologia: relações entre psicologia do trabalho e engenharia de produção. In: XXIV SIMPEP, Anais... Bauru SP, 2017, 14 p.

VIEIRA, C. E. C.; BARROS, V. A.; LIMA, F. de P. A. Uma abordagem da Psicologia do Trabalho, na presença do trabalho. Psicologia em Revista, Belo Horizonte, v. 13, n. 1, p.155-168, jun. 2007.

SCHWARTZ, Y. Histórico e conceitos da ergologia: entrevista com Yves Schwartz. Entrevista com Yves Schwartz, por Moacir Fernando Viegas. Reflexão \& Ação, v. 21, n. 1. p 327-340. 2013.

\footnotetext{
${ }^{i}$ Doutorando do Programa de Pós-graduação em Engenharia de Produção e Sistemas do CEFET/RJ, luizmpessanha@gmail.com

ii Docente do Programa de Pós-graduação em Engenharia de Produção e Sistemas do CEFET/RJ, o.aken@uol.com.br
} 